\title{
Democracia directa contra déficit democrático: el caso uruguayo
}

\author{
Direct Democracy against Democratic Deficit: \\ the Uruguayan Case
}

ALICIA LISSIDINI ${ }^{1}$ (Universidad Nacional de San Martín, Argentina)

Artículo recibido: 21 de noviembre de 2020

Solicitud de revisión: 11 de diciembre de 2020

Artículo aceptado: 27 de octubre de 2021

Lissidini, Alicia (2021). Democracia directa contra déficit democrático: el caso uruguayo. Recerca. Revista de Pensament i Análisi, 28(1), pp. 1-21.

doi: http://dx.doi.org/10.6035/recerca.5600

\section{Resumen}

En este artículo se analizan las funciones y los efectos que ha tenido la democracia directa en Uruguay, especialmente en los últimos años (2005-2021). Se estudian los plebiscitos y los referendos que efectivamente se realizaron y también aquellos que se iniciaron y no se concretaron por no lograr las firmas o las adhesiones necesarias. El principal objetivo de esta investigación es mostrar que los mecanismos de democracia directa constituyen una vía institucional que canalizan y dan voz al descontento social, contribuyendo a evitar el déficit democrático y el estallido social.

Palabras clave: democracia directa, Uruguay, democratización, movilización social, demandas sociales.

\section{Abstract}

This article analyzes the functions and effects of direct democracy in Uruguay, especially in recent years (2005-2021). It studies the plebiscites and referendums that were actually carried out, and also those that were initiated but did not materialize because they did not achieve the necessary signatures or adhesions. The main objective of this research is to show that the mechanisms of direct democracy constitute an institutional way to channel and give

\footnotetext{
${ }^{1}$ alicia.lissidini@gmail.com
} 
voice to social discontent, contributing to avoid the democratic deficit and the social outbreak

Key Words: Uruguay, Democratization, Mobilization, Protest, Political Parties.

\section{INTRODUCCIÓN}

Uruguay $^{2}$ es uno de los países más democráticos de América Latina según diversas mediciones y análisis. ${ }^{3} \mathrm{Su}$ proceso de redemocratización comenzó luego de la dictadura cívico-militar (1973-1984) impuesta después de un período de conflictos sociales, con altos niveles de polarización, de desvalorización de la democracia como régimen y de violencia política - tanto de sectores de izquierda como de derecha-, con represión por parte del Gobierno y restricciones a la democracia que condujeron al cierre del Parlamento y al golpe de Estado por parte de los miliares, que se concretó el 27 de junio de 1973 (Dutrénit, 1994). ${ }^{4}$

En este trabajo se plantea que, entre las dimensiones que hacen al buen funcionamiento de la democracia, la presencia de mecanismos de representación que eviten o reduzcan el déficit democrático ocupa un lugar central. Es decir, que la ciudadanía tenga respuestas a sus demandas por parte de los gobernantes, de los partidos y de quienes ocupan los cargos ejecutivos (Norris, 2011). Pero también son necesarios instrumentos que permitan el ejercicio de la voz y evite la salida, en el sentido que lo plantea Hirschman (1977), o sea, que existan formas de canalización de demandas sociales que habiliten la manifestación pública del descontento, sin que se produzcan estallidos sociales que conduzcan a la violencia social y política.

En el caso de Uruguay, los datos muestran que tanto el sistema de partidos políticos como los partidos mismos continúan cumpliendo un rol central, aunque no sin cambios (Lissidini y Pousadela, 2018). Las decisiones políticas más importantes suelen ser producto de negociaciones entre los diversos partidos y sus sectores políticos. ${ }^{5}$ En los últimos años, la inclusión del Frente Am-

\footnotetext{
${ }^{2}$ Una historia política muy completa de Uruguay puede leerse en Caetano y Rilla (1994).

${ }^{3}$ Entre ellos V-Dem y The Economist.

${ }^{4}$ Especialmente con el gobierno de Jorge Pacheco Areco - el «intruso político», como lo llama Real de Azúa - se rompe el «régimen de conciliación» tan característico de Uruguay, particularmente entre 1920 y 1950, como señala Carlos Real de Azúa (1964). Sobre el periodo previo al golpe se sugiere, véase Real de Azúa (1964 y 1984).

${ }^{5}$ Como señala Jorge Lanzaro (2013) Uruguay es una «democracia de partidos», goza de un sistema de partidos plural y competitivo, de larga vida, que alcanza un alto grado de institucionalización.
} 
plio (FA) en dichas negociaciones amplió la calidad de la democracia. Su papel fue central en la salida de la dictadura y en el acuerdo con los militares en el Gobierno, el llamado «Pacto del Club Naval» (Achard, 1992). ${ }^{6}$ Los grupos que otrora habían atentado contra las instituciones democráticas optaron por la vía electoral y desistieron de cualquier opción armada, como analiza Adolfo Garcé (Garcé, 2006). La mayoría de la izquierda, representada por el Frente Amplio, morigeró su programa, desradicalizándose (Moreira, Selios y Lizbona, 2010). En el Gobierno, el FA amplió la «agenda de derechos» y, a diferencia de otros gobiernos progresistas de la región, no menoscabó las libertades individuales, ni provocó desequilibrios entre los poderes del Estado (Lissidini, 2020).

Los partidos siguen siendo en Uruguay los principales mecanismos de representación, aunque, al igual que en la mayoría de las democracias, disminuyó la adhesión ciudadana hacia ellos y aumentó el descontento y la protesta. Parte de ese descontento se canalizó a través de las iniciativas de democracia directa y es sobre este aspecto sobre el que se centra el análisis de este artículo. No pretendemos establecer relaciones de causalidad, ni siquiera de correlación, entre la democratización y el uso de la democracia directa. Pero sí mostrar cómo, en este caso, el ejercicio de la democracia directa -incluso más allá de su resultado en las urnas- contribuyó a canalizar legalmente las demandas y desactivar conflictos que podrían haber escalado y estallado, como sucedió en varios países del mundo y, en particular, en América Latina recientemente.

Lo que aquí se presenta es una investigación original, que forma parte de una agenda más amplia, que incluye a toda América Latina.

En un contexto de fuerte descontento social, de enorme pesimismo político, la democracia directa reaparece en el debate político y constitucional como una posibilidad de contribuir a reducir la distancia entre la ciudadanía y las élites políticas, entre las necesidades sociales y la agenda gubernamental. De hecho, se está discutiendo en la actual Convención Constituyente en Chile. Se considera que el análisis del caso uruguayo puede contribuir a dicho debate, desde una investigación que no solo considera las consultas realizadas, sino las que no llegaron a concretarse, a pesar del esfuerzo realizado por la ciudadanía en la recolección de firmas.

\footnotetext{
${ }^{6}$ El Frente Amplio surgió como un movimiento que en 1971 aglutinó diversos sectores de izquierda y grupos escindidos de los partidos tradicionales, para luego transformarse en una coalición de partidos y, finalmente, funcionar como un partido tradicional catch all (Dutrénit, 1996).
} 


\section{LA DEMOCRACIA DIRECTA Y SUS POTENCIALES RIESGOS Y BENEFICIOS}

Para iniciar conviene realizar algunas precisiones conceptuales y legales. En este trabajo entendemos como democracia directa la participación ciudadana en consultas populares _llamados plebiscito, referendo o referéndum, según la constitución de cada país - a través del voto universal y voto secreto. Es decir, no se incluyen mecanismos que son propios de la democracia participativa. Pero sí incluimos como democracia directa la revocatoria de mandato, al igual que lo hace Yanina Welp y otros autores (Welp y Serdült, 2014).

La democracia directa puede constituirse en un mecanismo que contribuya a canalizar institucionalmente la protesta ciudadana, tal como se ha propuesto en otras investigaciones (Lissidini, 2014; Welp, 2016 y 2019). Los estudios muestran que los resultados dependen de quienes promueven las consultas populares - en especial si es el presidente o la ciudadanía-; de las condiciones políticas en que se realicen - grados de libertad, espacios de deliberación y tiempos para el debate-, así como su diseño institucional, es decir, los requisitos legales - como la cantidad de firmas exigidas, quiénes formulan la o las preguntas y los votos necesarios para su aprobación, entre otros aspectos.

En un contexto signado por lo que Rosanvallon (2009) llama una «desacralización» de la dimensión electoral de la democracia, junto con un cambio sustantivo en el concepto de pueblo, que ya no hace referencia a una masa homogénea, sino más bien a la suma o a la pluralidad de minorías que defienden sus derechos, los mecanismos de democracia directa se fueron incluyendo o ampliando en la mayoría de las constituciones latinoamericanas en las últimas décadas, como una forma de tratar de reducir el déficit democrático creciente, otorgándole más poder a la ciudadanía (Lissidini, 2011). La motivación explícita fue otorgarle a la ciudadanía mayores oportunidades para intervenir e influir en los asuntos públicos (Schneider y Welp, 2015).

Sin embargo, el caso uruguayo es diferente. Uruguay es el país con mayor cantidad de ejercicios de democracia directa en América Latina (Lissidini, 2015) y es el país que más tempranamente lo incorporó y lo ejerció a nivel nacional en la región. Su inclusión se realizó en un contexto de ampliación y posterior consolidación de la democracia y no de crisis de representación (Lissidini, 1998). Los partidos políticos, artífices de esa democracia, operaron en un sistema pluralista y tuvieron un alto grado de existencia organizacional, implantación social y continuidad histórica. En definitiva, la inclusión de la 
consulta y de la iniciativa popular contribuyó a un uso eficaz de la voz, evitando así la salida y reforzando la lealtad hacia los partidos políticos y las decisiones tomadas por ellos, siguiendo la teoría de Hirschman (1977). En el caso uruguayo, la democracia directa - a diferencia de otros países - no puede ser promovida por el Poder Ejecutivo y no existen limitaciones, ni restricciones, respecto a los temas que pueden ser propuestos por la ciudadanía; de hecho, se promovieron consultas relativas al presupuesto nacional, como un presupuesto mínimo para la educación.

La democracia directa ejercida desde la ciudadanía tiene características muy diferentes a cuando es iniciada y promovida por el Poder Ejecutivo. Sin embargo, no acordamos con la propuesta de David Altman (Altman, 2010) de distinguir las convocatorias desde arriba y desde abajo. Es discutible identificar a los representantes en el Parlamento como actores ubicados arriba. Pero, además, en el caso uruguayo se suelen conformar alianzas entre las organizaciones sociales y grupos políticos que ocupan bancas en la cámara de representantes para llevar adelante tanto referendos - acciones contra las leyes- como reformas constitucionales, llamados plebiscitos en este caso. Por otra parte, recordemos que en el caso uruguayo existe la obligación de ratificar o rechazar toda reforma constitucional por vía de la consulta popular - por cierto, el tipo de democracia directa que más se utiliza a nivel mundial-, es decir, el referéndum obligatorio, tal como señala Matt Qvortrup (2017).

En Uruguay, entonces, la Constitución permite a nivel nacional: la iniciativa ciudadana para proponer reformas constitucionales, ${ }^{7}$ la iniciativa ciudadana para derogar leyes (denominado referéndum) ${ }^{8}$ y la obligación de someter a consulta popular — llamado plebiscito_ - toda reforma constitucional. No exis-

${ }^{7}$ En el caso de los plebiscitos, la Constitución establece que «Por iniciativa del diez por ciento de los ciudadanos inscriptos en el Registro Cívico Nacional, presentando un proyecto articulado que se elevará al Presidente de la Asamblea General, debiendo ser sometido a la decisión popular, en la elección más inmediata. La Asamblea General, en reunión de ambas Cámaras, podrá formular proyectos sustitutivos que someterá a la decisión plebiscitaria, juntamente con la iniciativa popular» (artículo 331, inciso A). No hay en este caso ninguna limitación, ni control previo respecto a los temas a proponerse.

${ }^{8}$ En el caso del referéndum, se establece que podrá ser reformada, total o parcialmente, conforme a los siguientes procedimientos, que se resumen en estos artículos: art. 21.- El recurso de referéndum contra las leyes, instituido por el inciso segundo del artículo 79 de la Constitución de la República, podrá interponerse por el $25 \%$ del total de inscriptos habilitados para votar, contra la totalidad de la ley o, parcialmente, contra uno o más de sus artículos, precisamente individualizados, dentro del año de su promulgación [...]. Y art. 30.- «Podrán promover la interposición del recurso de referéndum ante la Corte Electoral compareciendo en un número no inferior al $2 \%$ de los inscriptos habilitados para votar, dentro de los ciento cincuenta días contados desde el siguiente al de la promulgación de la ley, cumpliendo con las condiciones establecidas en los numerales 1a a 5 - inclusive del artículo 21 de la presente ley». En cualquier caso, las firmas se presentan directamente a la Corte Electoral, como lo señala la Ley n.o 17244 (2000). 
ten las revocatorias de mandato, ni las consultas promovidas por el Ejecutivo, como ya se mencionó.

En función de la literatura sobre el tema, ${ }^{9}$ presentamos los riesgos que consideramos más importantes: 1) La deslegitimación del Parlamento en caso que la ciudadanía promoviera - y consiguiera - la derogación constante de leyes aprobadas por la mayoría parlamentaria; 2) El debilitamiento de los partidos políticos, si las organizaciones de la sociedad civil propusieran directamente propuestas de reforma constitucional; 3) La violación de los derechos de las minorías, si se revocaran por vía del referéndum las leyes que las amparan; 4) La toma de decisiones constante por sí o por no, sin posibilidad de deliberación y de decisiones negociadas.

Por otro lado, los posibles efectos positivos se podrían resumir en: 1) La canalización de las demandas y protestas por vías institucionales; 2) La ampliación de la agenda pública, al introducir temas que no están en la agenda de los partidos; 3) La resolución de conflictos sociales, cuando hay temas que dividen transversalmente a la ciudadanía; 4) El acercamiento de la ciudadanía a la política, al promover su participación en la recolección de firmas y el voto en las consultas populares (plebiscito y referéndum).

Tomando en cuenta estos potenciales riesgos y desafíos, se analizan entonces las iniciativas que se promovieron durante el período en que gobernó la izquierda en Uruguay, sobre las cuales no hay estudios publicados. A continuación, se presentan los temas planteados por la ciudadanía y el derrotero que tuvo cada iniciativa.

\subsection{La inseguridad y el punitivismo: una preocupación recurrente}

En el 2012, el informe del Latinobarómetro (Lagos y Dammert, 2012) señalaba que el $40 \%$ de la opinión pública lo consideraba el principal problema. En el 2018, el $20 \%$ de la población uruguaya temía ser víctima de un delito, por encima del promedio de América Latina, 16 \% (Corporación Latinobarómetro, 2018). Pero, más allá de la opinión pública, lo cierto es que las cifras de homicidios crecieron: de 143 en el 2014 a 218 en el 2018 (Ministerio del Interior de Uruguay, 2018). La tasa era de 11,8 en Uruguay en el 2018 (InSight Crime,

\footnotetext{
${ }^{9}$ Entre la extensa literatura, consideramos especialmente a: Lander y Brändle (1999); Mendelsohn y Parkin (2001); Lupia y Matsusaka (2004); Matsusaka (2004); Makin (2006); Qvortrup (2017); Della Porta, O’Connor, Portos y Subirats Ribas (2017); Hainmueller y Hangartne (2019); Welp (2016 y 2019); Welp y Ordóñez (2017) y El-Wakil y McKay (2020).
} 
2018), una tasa alta si consideramos que es un país sin presencia de violencia política, ni de narcotráfico a gran escala (como lo son Colombia y México).

El discurso sobre la necesidad de aumentar las penas para reducir los delitos contra las personas y contra la propiedad privada y, sobre todo, para bajar la edad de imputabilidad de ciertos delitos se instaló en los medios y en los debates políticos. Sectores de derecha y centro derecha propusieron dos reformas constitucionales en ese sentido. Para ello, juntaron las firmas requeridas y se consultó a la ciudadanía en octubre del 2014 y en octubre del 2019. En ambos casos, la consulta fue concomitante con las elecciones parlamentarias y presidenciales. En ninguna de las dos instancias se alcanzaron los votos necesarios, es decir, la adhesión de la mayoría de la ciudadanía (solo se votaba a favor).

En el 2014, la campaña fue liderada por Pedro Bordaberry, en ese momento el sector más conservador del PC. ${ }^{10}$ Como respuesta a la recolección de firmas, se constituyó a mediados del 2011 la Comisión por el No a la Baja, integrada por una multiplicidad de actores, colectivos políticos y sociales, ${ }^{11}$ pero el mayor protagonismo fue de los jóvenes menores de 30 años de las organizaciones sociales, sindicales y políticas y de muchos jóvenes sueltos - sin inserción partidaria-, que se acercaron a participar (Berri y Pandolfi, 2018: 37-56). Se visibilizaron las condiciones de vida de los adolescentes en situación de encierro, se debatió la situación de los «menores infractores» y de la minoridad en general, como surge del análisis de prensa.

El 26 de octubre de 2014, conjuntamente con las elecciones generales - presidenciales y parlamentarias-, la ciudadanía tuvo la posibilidad de adherirse a la reforma constitucional. La reforma no llegó a la cifra requerida, aunque obtuvo la adhesión del $46,81 \%$.

La iniciativa ciudadana que se puso a consideración de la ciudadanía en el 2019 fue promovida por sectores del PN - en especial por el dirigente Jorge Larrañaga-. ${ }^{12}$ Las principales medidas que se propusieron fueron: el levantamiento de la prohibición de los allanamientos nocturnos si existe orden judicial, el cumplimiento completo de las penas en los delitos graves, la prisión

\footnotetext{
${ }^{10}$ Pedro Bordaberry es hijo de Juan María Bordaberry, quien fuera presidente de la República y luego diera un autogolpe entre 1973 y 1976 . Fue condenado por delitos de lesa humanidad.

${ }^{11}$ Integraron la Comisión Nacional No a la Baja diversos grupos sociales y culturales, centros de investigación y de acción, organizaciones no gubernamentales, organizaciones sindicales, estudiantiles y organizaciones partidarias de todo el espectro político (especialmente del Frente Amplio, pero también de partidos tradicionales) de Montevideo y de otros departamentos de Uruguay.

${ }^{12}$ Jorge Larrańaga fue ministro del Interior del gobierno de Luis Lacalle Pou hasta su fallecimiento el 22 de mayo de 2021.
} 
perpetua revisable en los casos de delitos gravísimos y la creación de una Guardia Nacional integrada por militares. Las firmas - unas 400 ooo- se presentaron en febrero del 2019 y buena parte de su recolección la hicieron grupos de adultos mayores y militantes del PN.

No a la Reforma —organización que articuló la oposición a la reforma- se propuso: evitar la aprobación de la reforma constitucional propuesta por la Campaña Vivir sin Miedo; evitar el avance de la estrategia represiva y punitivista, tanto en términos prácticos como discursivos; producir colectivamente otro marco de comprensión para el problema de la inseguridad ciudadana, y fomentar el debate público sobre la temática de seguridad y sus diferentes dimensiones. ${ }^{13}$

Al igual que en el 2014, artistas e intelectuales se manifestaron en contra, así como varias organizaciones de la sociedad civil. En esta ocasión, la cantidad de votos - adhesiones - tampoco alcanzó la mayoría absoluta para lograr su aprobación, pero también obtuvo el 46,7\% de apoyo y, a diferencia del 2014, hubo denuncias de falta de papeletas en las urnas. ${ }^{14}$

El Poder Ejecutivo volvió a ceder espacio en los medios audiovisuales a quienes hicieron campaña a favor, como en contra. El resultado fue muy similar al plebiscito del 2014: a menor porcentaje de votos al Frente Amplio, mayor el respaldo a la reforma. En el 2019 surgió un nuevo partido - Cabildo Abierto-, liderado por Manini Ríos, militar y exjefe del Ejército desde el 2015 hasta el 2019, quien apoyó la propuesta de reforma y, en particular, la participación del Ejército en el combate al narcotráfico y a la inseguridad. El mayor apoyo a la reforma fue de los departamentos ubicados lejos de la capital, a pesar de que es en Montevideo donde se registran más homicidios y rapiñas: $56,7 \%$ de los asesinatos consumados en el primer semestre de este año se cometieron allí, mientras que en Rivera, donde la reforma obtuvo su votación más alta, apenas ocurrió $1,16 \%$ de los homicidios durante el primer semestre del año. ${ }^{15}$ Rivera es justamente el departamento donde más votos obtuvo Cabildo Abierto en las elecciones del 2019 (Lissidini, 2020).

El nuevo gobierno, que asumió en marzo del 2020, aprobó una serie de leyes que aumentaron las penas y crearon nuevos delitos - como la ocupación indebida de los espacios públicos, resistencia al arresto y agresión a trabajado-

\footnotetext{
${ }^{13}$ Fuente: Página de la organización No a la Reforma, https://www.noalareforma.uy/index.html\#

${ }^{14}$ Fuente: El Observador, 27 de octubre de 2019, https://www.elobservador.com.uy/nota/presunto-boicot-ala-reforma-vivir-sin-miedo-con-hurto-de-papeletas-en-los-circuitos-electorales-20191027183913

${ }^{15}$ Fuente: La Diaria, 28 de octubre de 2019, https://ladiaria.com.uy/elecciones/articulo/2019/10/la-reformavivir-sin-miedo-tuvo-su-aprobacion-mas-alta-entre-votantes-blancos-y-de-cabildo-abierto/
} 
res de la educación, la salud y el transporte, entre otros- en el marco de lo que se dio a llamar la Ley de Urgente Consideración (LUC). ${ }^{16}$ Dichas normas se aprobaron por mayoría parlamentaria, con los votos de los partidos de centroderecha y derecha, los que conforman la llamada «coalición multicolor» que le dio la victoria a Luis Lacalle Pou en el balotaje contra el candidato de izquierda del Frente Amplio en noviembre del 2019.

En definitiva, el ejercicio de la democracia directa fue un fiel reflejo de la división ideológica de la ciudadanía en materia de políticas de seguridad. La campaña Vivir sin miedo no alcanzó las adhesiones necesarias para reformar la Constitución, pero tuvo un gran apoyo de la ciudadanía. El principal líder de la campaña - Jorge Larrañaga - fue nombrado ministro del Interior por el gobierno del presidente Luis Lacalle Pou y varias de las medidas promovidas en la iniciativa, incluidas en la Ley de Urgente Consideración, fueron aprobadas en los primeros meses del 2020.

\section{LAS INICIATIVAS CONSTITUCIONALES QUE NO SE CONCRETARON}

No hay registros ni investigaciones actualizadas de las iniciativas que se impulsaron y que no llegaron a convertirse en plebiscito o en referéndum. Este artículo se propone hacer una revisión de las más recientes, dividiendo las iniciativas en: referéndum contra las leyes aprobadas en el Parlamento y las iniciativas que proponen una reforma constitucional, llamadas plebiscito en Uruguay.

\subsubsection{Referendos contra derechos adquiridos: aborto y ley integral de perso- nas transgénero}

Uno de los referendos que no llegó a ser tal fue el intento por derogar la ley 18897 , promulgada el 22 de noviembre de 2012, que permite la interrupción del embarazo a las ciudadanas uruguayas naturales y legales, y las mujeres extranjeras con más de un año de residencia en el país, dentro de las 12 sema-

\footnotetext{
${ }^{16}$ Los cambios más importantes que introdujo la LUC pueden leerse en: «Inflación penal en la LUC: el debate y los cambios punitivos, 11 de agosto de 2020». Disponible en:

https://www.180.com.uy/articulo/83492_inflacion-penal-en-la-luc-el-debate-y-los-cambios-en-las-penas
} 
nas de gravidez. ${ }^{17}$ Aun antes de ser aprobada, el PN lanzó una campaña para que se iniciara un proceso de recolección de firmas para someter a referéndum dicha ley. ${ }^{18}$ En este caso se utilizó la vía rápida, es decir, se presentó el $2 \%$ del padrón electoral - unas 52 ooo firmas - para que la Corte Electoral convocara un prerreferéndum. En los hechos es más difícil de alcanzar, pues requiere que el $25 \%$ concurra a las urnas. Aunque una encuesta presentada por CIFRA afirmaba que la mayoría de la ciudadanía estaba a favor del referéndum (66\%) tan solo el 8,7 \% concurrió a habilitar la consulta. ${ }^{19}$ Lo llamativo de este caso es que cuatro potenciales candidatos de los principales partidos políticos: Pedro Bordaberry del PC, Jorge Larrañaga del PN, Pablo Mieres del Partido Independiente y Tabaré Vázquez del FA votaron para habilitar la consulta. Vale acotar que la Comisión Prorreferéndum solicitó al Poder Ejecutivo la utilización de la cadena nacional de radio y televisión para presentar su propuesta, pero fue denegada por el entonces presidente José Mujica.

En definitiva, el tema se dio por concluido con este intento. Más allá de la opinión que se expresaba en las encuestas, la ciudadanía no concurrió a las urnas para abrir el debate sobre un derecho ya adquirido. Lo mismo sucedió con la ley n. ${ }^{\mathrm{o}} 19684$, Ley integral para personas trans. ${ }^{20}$ La Comisión Nacional Proderogación de la Ley Trans recogió el 2 \% de las firmas del padrón electoral, lo que habilitó a convocar una consulta para permitir un referéndum. Al igual que en el caso mencionado antes, se requería el voto del $25 \%$ del padrón para habilitar el voto. Aunque algunas encuestas registraban un leve predominio de quienes se oponían a la ley por sobre quienes estaban a favor, la concurrencia fue exigua: $9,9 \%$ de los habilitados para votar.

Las organizaciones y las personas que promovieron la derogación del derecho al aborto y de la ley trans se ubicaban a la derecha del espectro político. Contra la interrupción del embarazo se movilizaron los grupos Provida de la Iglesia Católica, con el tímido apoyo del Partido Nacional (PN) y del Partido Colorado (PC), aunque menos, pues muchos batllistas tienen una postura his-

\footnotetext{
${ }^{17}$ Uno de los trabajos que analiza de manera interdisciplinaria el aborto puede leerse en Johnson, López Gómez, Sapriza, Castro y Arribeltz (2011).

${ }^{18}$ Fuente: «Lanzan campaña de firmas contra el aborto y evalúan acción jurídica» $\mathrm{PN}$ s/f https://www.partidonacional.org.uy/portal/index.php/9-noticias/256-lanzan-campana-de-firmascontra-el-aborto-y-evaluan-accion-juridica

${ }^{19}$ Fuente: «Uruguayos votarían a favor de la ley de aborto». En Perspectiva, 15 de noviembre de 2012 https://www.180.com.uy/articulo/29961_Uruguayos-votarian-a-favor-de-ley-sobre-aborto

${ }^{20}$ Fuente: «Alcanzaron las firmas para iniciar el proceso de derogación de la Ley Integral para Personas Trans». La Diaria, 29 de marzo de 2019. https://ladiaria.com.uy/articulo/2019/3/alcanzaron-las-firmas-parainiciar-el-proceso-de-derogacion-de-la-ley-integral-para-personas-trans/
} 
tóricamente favorable al aborto. En el caso de la ley trans, la derogación fue promovida por un grupo autodenominado «Todos somos iguales» y fue impulsada por el precandidato del PN Carlos Lafigliola (Movimiento Adelante Provida) y por el diputado nacionalista Álvaro Dastugue (Esperanza Nacional), ambos sectores minoritarios dentro del PN. El FA se pronunció en contra de la derogación de los derechos adquiridos. En estos casos, el ejercicio de la democracia directa no tuvo consecuencias negativas sobre las minorías; por el contrario, estos intentos otorgaron mayor legitimidad a las leyes aprobadas por mayoría en el Parlamento y generaron un consenso social respecto a no retroceder en materia de derechos adquiridos.

De hecho, en el documento «Compromiso por el país», ${ }^{21}$ presentado por la coalición multicolor de cara al balotaje y en respaldo al entonces candidato Luis Lacalle Pou, se señala que uno de los compromisos era «Mantener la legislación vigente y continuar trabajando en beneficio de grupos que han sido históricamente perjudicados por su género, por su origen étnico, por su orientación sexual o por otras características personales».

2.2.2. Referéndum contra la ley de riego: movilización social sin apoyo partidario

Otra iniciativa que no llegó a la instancia de consulta popular fue el intento por derogar la Ley n.․ 19 553, «Riego con destino agrario». Dicha ley fue impulsada por el Ministerio de Ganadería, Agricultura y Pesca (MGAP) para aumentar la disponibilidad de agua y mitigar los efectos de su variabilidad temporal sobre la producción agropecuaria y fue aprobada por amplia mayoría en el Parlamento. A diferencia del caso anterior, la vía utilizada fue la llamada lenta, es decir: la ciudadanía tenía un año para juntar el $25 \%$ de firmas para promover directamente un referéndum (y no un prerreferéndum como el caso del aborto). O sea, tenía más tiempo, pero la exigencia era mayor.

La aprobación de la ley generó - tal vez por primera vez en la historiauna fuerte oposición entre la academia - representada especialmente por investigadores de la Universidad de la República- y el Gobierno del Frente Amplio. ${ }^{22}$ También enfrentó a las organizaciones ambientales junto al sindica-

\footnotetext{
${ }^{21}$ Fuente: «¿Qué dice el documento firmado por la coalición y cuáles fueron los cambios para el acuerdo final? Modificaciones en seguridad, educación y “continuar” con la agenda de derechos: los detalles del texto firmado por los líderes de la oposición». El Observador, 5 de noviembre de 2019.

${ }^{22}$ Fuente: «Mesa de debate sobre Ley de Riego organizada por la Facultad de Ciencias». El Telégrafo, 27 de noviembre de 2017, https://www.eltelegrafo.com/2017/11/mesa-de-debate-sobre-ley-de-riego-en-la-
} 
to de los trabajadores de OSE (Obras Sanitarias de Estado) contra la izquierda representada en el Gobierno. La ley contó, además, con el apoyo del Banco Mundial, lo cual también generó críticas desde algunos sectores de izquierda. Es decir, la ley fue cuestionada por diversas bancadas, pero finalmente aprobada por casi la unanimidad.

Durante el debate parlamentario y luego de la aprobación de la ley, se movilizaron las organizaciones Redes-Amigos de la Tierra y la Comisión en Defensa del Agua y de la Vida, entre otras, quienes consideraron —además de los aspectos mencionados por los legisladores- que la ley violaba el artículo 47 de la Constitución de la República porque habilitaba la mercantilización del agua.

La Comisión por el Agua y la Vida ${ }^{23}$ llevó adelante la campaña de recolección de firmas. Si bien las organizaciones ambientales recogieron firmas y tuvieron el apoyo - al menos formal- de diversos grupos y asociaciones, no contó con el respaldo de ningún partido político importante y solo parte del sindicato de OSE se movilizó activamente. Hubo debates en las redes sociales y manifestaciones en la calle, pero no contaron con los recursos económicos y políticos para visibilizar el reclamo. Se juntaron unas 300 ooo firmas, menos de la mitad de las requeridas.

La Comisión anunció que seguirá intentando derogar la ley a través de la declaración de inconstitucionalidad. Asimismo, se siguen registrando manifestaciones en contra de la ley de riego, conjuntamente con otras protestas, como la movilización contra la instalación de una nueva pastera en Uruguay. El 22 de marzo de 2019, a propósito del Día del Agua, se realizó una importante manifestación pública en un contexto en el que los ríos de Uruguay muestran mayor presencia de cianobacterias y se registran denuncias de problemas con el agua potable. ${ }^{24}$ Es decir, la agenda ambiental y el conflicto entre modelos de desarrollo y derecho ambiental adquirieron mayor relevancia. Pero, al igual que sucedió con otros gobiernos progresistas de la región (Svampa, 2013), este conflicto colocó al Frente Amplio - al menos en este tema- en contra de los derechos del ambiente y de sus defensores.

facultad-de-ciencias/. «Sectores del FA y la academia advierten que la eventual Ley de Riego afectará la biodiversidad». La República, 14 de octubre de 2017. http://www.lr21.com.uy/comunidad/1348114proyecto-ley-riego-danos-biodiversidad-agua-potable

${ }^{23}$ Sobre la integración formal de la Comisión, véase en su página: http://www.ffose.org.uy/aguayvida/web/content/comision.html

${ }^{24}$ Fuente: «Este 22 en la calle, por el agua y por la vida». La Diaria, 22 de marzo de 2019, https://ladiaria.com.uy/articulo/2019/3/este-22-en-la-calle-por-el-agua-y-por-la-vida/ 
Algunos antecedentes de movilizaciones ciudadanas ambientales en Uruguay fueron: el freno a la instalación de la minera Aratirí (extracción de hierro a cielo abierto ${ }^{25} \mathrm{y}$, como consecuencia la paralización del proyecto de aguas profundas que requería Aratirí (2013-2015), la movilización en el 2018 contra la instalación de una empresa de transporte fluvial en el dique Mauá protagonizada por la Asamblea Permanente por el Barrio $\operatorname{Sur}^{26}$ y que finalizó con la cancelación de la obra — aprobada en el Parlamento por la bancada del Frente Amplio- $\mathrm{y}$ ahora $(2020)^{27}$ la movilización contra la instalación de una nueva pastera, una resistencia que adquiere cada vez mayor visibilidad y que también utiliza las vías legales.

En definitiva, el ejercicio de la democracia directa dio mayor visibilidad a la ya preexistente agenda ambiental y, aunque no logró su cometido, el tema adquirió estatus político. Es decir, el intento de ejercicio de democracia no deslegitimó lo resuelto por el Parlamento, pero dejó en claro que existen cuestionamientos en la sociedad a lo resuelto. Dio voz al descontento de un grupo minoritario, al menos por ahora, de la ciudadanía.

\subsubsection{Otras iniciativas en el camino}

Hubo otras iniciativas que se plantearon pero que no prosperaron. Entre ellas, la que propuso eliminar las Administradoras de Fondos de Ahorro Previsional (AFAP) en el 2016 y la que pretendía prohibir la minería a cielo abierto en el 2014. También se inició una recolección de firmas contra la «bancarización obligatoria». Fue promovida por empresarios y comerciantes agrupados en la Cámara Regional de Empresarios y Comerciantes del Este (CRECE) y también por la Comisión Proplebiscito «para decirle no a la inclusión finan-

\footnotetext{
${ }^{25}$ Este grupo nació en el 2013 y tenía como uno de sus objetivos una reforma constitucional — plebiscitoque prohibiera la minería a cielo abierto. Fuente: http://www.guayubira.org.uy/2016/08/uruguay-librede-megamineria/

${ }^{26}$ Fuente: https://www.enperspectiva.net/enperspectiva-net/movimiento-opuesto-terminal-zona-del-diquemaua-patrimonio-horizonte-maritimo-la-visual-la-gente-visita-lugar-la-condicion-policlasista/

${ }^{27}$ En el momento de corregir este artículo (octubre del 2021), se están juntando firmas para promover una reforma constitucional que propone: 1) Declarar nulo el contrato con la empresa finlandesa UPM y sus acuerdos complementarios; 2) Regular los contratos de inversión hechos por el Estado, haciendo obligatoria la aprobación legislativa en los casos en que el contrato implique sometimiento del país a jurisdicción extranjera, estabilidad jurídica (es decir, garantía de que ninguna ley o norma disminuirá las ganancias de la empresa) o cuando se pongan a cargo del Estado obligaciones que se extiendan más allá del período de gobierno en curso al firmar el contrato; 3) Disminuir del $25 \%$ al $10 \%$ del padrón electoral la cantidad de firmas necesarias para promover un referéndum contra las leyes, lo que facilitará que esos contratos de inversión puedan ser impugnados por la ciudadanía aun en caso de tener la aprobación legislativa (Grupo Uruguay Soberano).
} 
ciera obligatoria». Luego se fueron sumando otras organizaciones como el Centro de Almaceneros Minoristas, Baristas, Autoservicistas y Afines del Uruguay (CAMBADU), la Organización de Jubilados y Pensionistas del Uruguay (ONAJPU), Un Solo Uruguay (empresarios y trabajadores relacionados al sector agropecuario) y otras organizaciones opositoras al gobierno del Frente Amplio.

Esta demanda también fue recogida por el gobierno de Luis Alberto Laca1le Pou y la coalición multicolor e incorporada a la Ley de Urgente Consideración (LUC) en el 2020. Con el voto de los integrantes de dicha coalición se derogó la bancarización obligatoria (incorporada durante el gobierno del Frente Amplio) y, a partir de la nueva normativa empresarios y trabajadores, deberán acordar la forma de pago de los salarios y, por consiguiente, no será obligatorio cobrar a través de una modalidad electrónica. Es decir, la democracia representativa escuchó la demanda expresada por un sector de la sociedad civil y la transformó en ley.

\section{HACIA UN REFERÉNDUM PARA LA DEROGACIÓN PARCIAL DE LA LEY DE URGENTE CONSIDERACIÓN ${ }^{28}$}

Las firmas recogidas por la Comisión Prorreferéndum fueron entregadas en tiempo y forma a la Corte Electoral encargada de verificar su validez, proceso que, si bien no ha finalizado, se encuentra bastante adelantado. Todo indica que habrá referéndum con voto obligatorio en marzo o abril del 2022.

Al igual que en 1992 contra la privatización de las empresas públicas se promovió la derogación total y parcial. Como en aquella oportunidad, primó la segunda, como señal de moderación y de negociación. La Intersocial —que reúne al PIT-CNT, FUCVAM, FEUU, Intersocial Feminista y otras organizaciones- fue uno de los colectivos que más tempranamente proclamó en público iniciar el camino de interposición del referéndum contra la Ley de Urgente Consideración (LUC) a través del mecanismo largo: recolección del $25 \%$. Tam-

\footnotetext{
${ }^{28}$ Para la elaboración de este apartado se realizaron tres entrevistas: a un integrante de la Corte Electoral de Uruguay, a una integrante de Intersocial Feminista, que formó parte de la negociación con el sindicalismo y con el Frente Amplio en relación al referéndum, y a un dirigente frenteamplista con cargo de responsabilidad política. Este referéndum forma parte de la investigación actual que coordino y que está integrada por estudiantes de la carrera de sociología de la Facultad de Ciencias Sociales de la Universidad de la República (Grupo de Investigación del Referéndum contra la Ley de Urgente).
} 
bién fue la que más activamente protestó contra dicha ley, cuando se estaba votando en el Parlamento.

Así como en 1992 FANCAP tuvo un rol central, en esta oportunidad el secretariado del PIT-CNT también, al advertir los riesgos que implicaba la posible aprobación de la LUC por sus efectos privatizadores sobre diversas empresas estatales. Lo novedoso en esta oportunidad fue que las feministas entraron en escena a través de la Intersocial Feminista. Fueron ellas quienes defendieron el referéndum y la inclusión de ciertos artículos referidos a seguridad —al igual que lo hizo cada sector social- y la negociaron con el FA, partido que inicialmente se opuso con tenacidad a la propuesta de activar la democracia directa (fundamentalmente por temor a no alcanzar las firmas requeridas).

Finalmente, el FA terminó accediendo ante las demandas sociales. En la negociación se dejó de lado la posibilidad de ir por un referéndum total. De cualquier manera, se mantuvieron las dos iniciativas, resultado que, lejos de confundir a la ciudadanía, como señalaron algunos analistas, mostró un camino moderado y uno más radical.

La gran mayoría de los analistas políticos y casi todos los políticos —en especial los del FA- vaticinaron la derrota de la iniciativa. El contexto de pandemia, de alta popularidad del presidente Luis Lacalle Pou, de escasa información pública sobre la Ley de Urgente Consideración y sobre la recolección de firmas y de un Frente Amplio adormecido no parecía el mejor escenario para recoger 700 ooo firmas. Sin embargo, una vez que se llegó a un acuerdo y la campaña se inició, la movilización del sindicalismo, de las organizaciones sociales y del FA le dieron visibilidad a la campaña. A juzgar por los datos, el Frente habría aportado el $57 \%$ de las firmas y el sindicalismo y las organizaciones, el resto; lo que habla de la centralidad de la militancia frenteamplista, pero también de una necesidad mutua. En este caso, la iniciativa surgió a pesar de los líderes del FA. Es decir, las organizaciones sindicales y sociales le impusieron al FA una agenda, pero, sin este actor político, no se hubiera alcanzado la meta.

Pero este referéndum tuvo características inéditas. Las firmas debieron juntarse en el peor momento de la pandemia en Uruguay: entre los primeros días de enero y el 8 de julio de 2021, cuando la cantidad de personas fallecidas, internadas y contagiadas tuvo su récord histórico. Durante ese período estuvieron prohibidas las aglomeraciones, los actos públicos, los espectáculos, los partidos de fútbol, los recitales, los debates públicos presenciales... es decir, todos los eventos sociales en los que se suelen juntar firmas. Las coordinadoras por la derogación total y parcial solicitaron una prórroga para obtener un 
plazo mayor, que les fue denegada. Además, los principales medios de comunicación tendieron a ignorar la campaña de recolección de firmas, aunque en los barrios y en las principales avenidas se notaba un número cada vez mayor de activistas, que con el tiempo se hicieron más visibles, tanto que, finalmente, terminaron siendo noticia.

El día 8 de julio la noticia fue la llegada de casi 800 ooo firmas para convocar a derogar parcialmente la LUC, una cifra inesperada incluso para los y las propias activistas. Un hito que sacó de su zona de confort al Gobierno y representa un enorme desafío para la oposición.

La campaña a favor de la derogación parcial, sí, y en contra, no, ya se inició dada la alta confianza que se tiene en la Corte Electoral de Uruguay.

\section{CONCLUSIÓN. DEMOCRACIA DIRECTA EN URUGUAY: EVITAR EL ESTALLIDO Y AMPLIAR LA AGENDA}

La democracia directa sigue siendo en Uruguay un instrumento que utilizan los partidos políticos para promover reformas constitucionales y también para intentar derogar leyes aprobadas en el Parlamento. Los partidos políticos - por identidad política y también por el manejo de recursos- continúan jugando un rol central para promover y apoyar la democracia directa. Sin embargo, en los últimos años, aumentó el protagonismo de las organizaciones de la sociedad civil y en algunos casos obligaron a los partidos a posicionarse o se independizaron de los partidos políticos. ${ }^{29}$ Surgieron y se ampliaron las organizaciones de la sociedad civil relacionadas con los derechos humanos, generales y particulares, como las organizaciones que protegen los derechos de las personas privadas de libertad, los derechos ambientales, los de las mujeres, las comunidades LGTBIQ, los grupos de jóvenes, entre otros. Aunque con menor presencia que en otros países de la región, también en Uruguay las organizaciones como Provida y, más recientemente, Un Solo Uruguay, $3^{\circ}$ adquirieron visibilidad y poder junto con los grupos pentecostales y los evangélicos (Lissidini, 2020).

\footnotetext{
${ }^{29}$ Históricamente el Frente Amplio surgió en alianza con la lucha sindical y fue incorporando las demandas de diferentes grupos sociales y culturales, como las de las feministas y las del colectivo LGTBIQ, entre otras. Durante su gobierno se aprobó una amplia agenda de derechos (Lissidini, 2020).

${ }^{30}$ Un Solo Uruguay es un grupo de diferente filiación política partidaria y de demandas diversas, pero que tiende a representar los intereses del sector agropecuario y se identifica mayoritariamente con el centro y centro-derecha del espectro político partidario.
} 
Las organizaciones de la sociedad civil, en forma solitaria, conjuntamente con partidos o con el apoyo partidario, utilizaron los mecanismos institucionales para conducir la protesta. La canalización de la insatisfacción ciudadana por vías legales conlleva una serie de beneficios tanto para las personas que protestan, como para la democracia en su conjunto. Se permite el ejercicio de la $v o z$, sin que se produzcan hechos de violencia y sin promover una salida del proceso democrático. En el caso de la democracia directa, la ciudadanía tiene la posibilidad de ejercer su función constituyente - mediante el plebiscito- $\mathrm{y}$ también participar ejerciendo una función legislativa a través de la iniciativa de reforma y del referéndum.

En definitiva, consideramos que, independientemente de los temas en cuestión, los plebiscitos y los referendos en Uruguay han contribuido a ampliar la democracia, introducir temas en la agenda y expresar opiniones contrarias a las leyes aprobadas. Esta afirmación surge no solo del análisis de estos casos, sino del estudio de la historia de la democracia directa en Uruguay desde sus orígenes.

Los partidos políticos y el Gobierno tienen la posibilidad de escuchar las demandas de forma más clara. Si bien en el caso uruguayo hay una cultura política que promueve la búsqueda de consensos entre los partidos políticos y también hay puentes de diálogo con las organizaciones de la sociedad civil y con el conocimiento experto, creemos que se deberían reforzar estos canales y así utilizar los mecanismos de democracia directa y otras vías institucionales, una vez agotadas las vías informales.

\section{BIBLIOGRAFÍA}

Achard, Diego (1992). La transición en Uruguay. Montevideo: IngenioServicio de Comunicación y Marketing

Altman, David (2010). Direct Democracy Worldwide. Cambridge: Cambridge University Press.

Berri, Mateo y Pandolfi, Jimena (2018). Movimiento «No a la baja». Construcción estratégica de la identidad colectiva. Revista de Ciencias Sociales DS-FCS, 31(42), 37-56. Recuperado de: http://www.scielo.edu.uy/scielo.php?script=sci_arttext\&pid=So797 $-55382018000100037 \& \operatorname{lng}=$ es\&nrm=iso 
Caetano, Gerardo y Rilla, José (1994). Historia contemporánea del Uruguay. De la Colonia al Mercosur. Montevideo: CLAEH-Fin de Siglo.

Corporación Latinobarómetro (2018). Informe Latinobarómetro 2018. Recuperado de: https://www.latinobarometro.org/latOnline.jsp

Della Porta, Donatella, O'Connor, Francis, Portos, Martín y Subirats Ribas, Ana (2017). Social Movements and Referendums from Below:

Direct Democracy in the Neoliberal Crisis. Bristol: Policy Press.

Dutrénit, Silvia (1994). El maremoto militar y el archipiélago partidario.

Testimonios para una historia reciente de los partidos políticos uruguayos. Montevideo: ECS/Instituto Mora.

Dutrénit, Silvia (1996). El Frente Amplio y la reproducción de la identidad política. Nueva Sociedad, 144, 126-137.

El-Waki, Alice y McKay, Spencer (2020). Introduction to the Special Issue «Beyond 'Direct Democracy': Popular Vote Processes in Democratic Systems». Representation, 56(4), 435-447. doi: https://doi.org/10.1080/00344893.2020.1820370

Garcé, Adolfo (2006). Donde hubo fuego. El proceso de adaptación del MLN-Tupamaros a la legalidad y a la competencia electoral (1985-2004). Montevideo: Fin de Siglo.

Hainmueller, Jens y Hangartne, Dominik (2019). Does Direct Democracy Hurt Immigrant Minorities? Evidence from Naturalization Decisions in Switzerland. American Journal of Political Science, 63(3), 530-547.

Hirshman, Albert O. (1977). Salida, voz y lealtad. México: Fondo de Cultura Económica.

InSight Crime (2018). Balance de InSight Crime sobre los homicidios en 2018. Recuperado de: https://es.insightcrime.org/noticias/analisis/ balance-de-insight-crime-sobre-los-homicidios-en-2018/

Johnson, Niki, López Gómez, Alejandra, Sapriza, Graziela, Castro, Alicia y Arribeltz, Gualberto (2011). (Des)penalización del aborto en Uruguay: prácticas, actores y discursos. Abordaje interdisciplinario sobre una realidad compleja. Montevideo: CSIC. Recuperado de: 
https://www.colibri.udelar.edu.uy/jspui/bitstream/20.500.12008/76 19/1/Despenalizacion\%2odel\%2oaborto\%2oen\%2oUruguay.pdf Lagos, Marta y Dammert, Lucía (2012). La Seguridad Ciudadana. El problema principal de América Latina. Informe Corporación Latinobarómetro. Recuperado de: https://www.latinobarometro.org /documentos/LATBD_La_seguridad_ciudadana.pdf

Lander, Andreas y Brändle, Michael (1999). Does Direct Democracy Matter for Political Parties? An empirical test in the Swiss Cantons. Party Politics, 5(3), 283-302.

Lanzaro, Jorge (2013). Continuidad y cambios en una vieja democracia de partidos: Uruguay (1910-2010). Opinião Pública, $19(2)$. Recuperado de: https://doi.org/10.1590/So104-62762013000200001 Lissidini, Alicia (1998). Los plebiscitos uruguayos durante el siglo XX: ni tan autoritarios ni tan democráticos. Cuadernos del Claeh 81-82. Revista Uruguaya de Ciencias Sociales, 23(1-2), 195-217.

Lissidini, Alicia (2011). Democracia directa en Latinoamérica: entre la delegación y la participación. Buenos Aires: CLACSO. Recuperado de: http://bibliotecavirtual.clacso.org.ar/ar/libros/becas/lisidini/lisidi ni.pdf

Lissidini, Alicia (2014). Paradojas de la participación en América Latina: ¿puede la democracia directa institucionalizar la protesta? En Lissidini, Alicia, Welp, Yanina y Zovatto, Daniel (comp.). Democracias en movimiento. Mecanismos de democracia directa $y$ participación en América Latina (71-107). México: Universidad Nacional Autónoma de México, Centro de Investigaciones sobre Democracia Directa, Instituto Internacional para la Democracia y Asistencia Electoral.

Lissidini, Alicia (2015). Democracia directa en América Latina: avances y contradicciones. En Minnaert, Anja y Endara, Gustavo (coord.). Democracia participativa e izquierdas. Logros, contradicciones $y$ desafíos (120-187). Quito: Fundación Friedrich Ebert, Quito. Recuperado de: http://nuso.org/documento/democracia-directaen-america-latina-avances-contradicciones-y-desafios/ 
Lissidini, Alicia (2020). «Uruguay: sin déficit democrático y con giro electoral». Revista Eurolatinoamericana de análisis social y político, 1(1), 187-198. Recuperado de: http://www.ojs.unsj.edu.ar/index.php/relasp/article/view/513

Lissidini, Alicia y Pousadela, Inés (2018). El experimento uruguayo: Actores políticos y sociales en el proceso de regulación del cannabis. Revista Perspectivas de Políticas Públicas, 14, 367-292. Recuperado de: http://revistas.unla.edu.ar/perspectivas/article/vie $\mathrm{w} / 1918$

Lupia, Arthur y Matsusaka, John (2004). Direct Democracy: New Approaches to Old Questions. Annual Review of Political Science, 7 , 463-482.

Makin, Jeffrey (2006). Are ballot proposition spilling over onto candidate elections? California: University of Southern California. Recuperado de: http://www.iandrinstitute.org/docs/REPORT\%20 2006-2\%20Spillovers.pdf

Matsusaka, John (2004). For the Many or the Few. The Initiative, Public Policy, and American Democracy. Chicago: The University of Chicago Press.

Mendelsohn, Matthew y Parkin, Andrew (eds.) (2001). Referendum Democracy. Citizens, Elites and Deliberation in Referendum Campaigns. London: Palagrave.

Ministerio del Interior de Uruguay (2018). Homicidios 1.. de enero al 31 de diciembre (2017-2018). Montevideo: Observatorio Nacional sobre violencia y criminalidad. Recuperado de: https://www.minterior.g ub.uy/images/2019/PDF/hom_2018.pdf

Moreira, Constanza, Selios, Lucía y Lizbona, Alexandra (2010). La renovación programática del Frente Amplio: una mirada al proceso reciente (2004-2009). Montevideo: Udelar.

Norris, Pippa (2011). Democratic Deficit: Critical Citizens revisited. Cambridge: Cambridge University Press.

Qvortrup, Matt (2017). The Rise of Referendums: Demystifying Direct Democracy. Journal of Democracy, 28(3), 141-152. 
Real de Azúa, Carlos (1964). El impulso y su freno. Tres décadas de batllismo y la crisis uruguaya. Montevideo: Banda Oriental.

Real de Azúa, Carlos (1984). Uruguay: ¿Una sociedad amortiguadora? Montevideo: CIESU-Banda Oriental.

Rosanvallon, Pierre (2009). La legitimidad democrática. Imparcialidad, reflexividad, proximidad. Buenos Aires: Manantial.

Schneider, Cecilia y Welp, Yanina (2015). Diseños institucionales y (des)equilibrios de poder: las instituciones de participación ciudadana en disputa. Revista Mexicana de Ciencias Políticas y Sociales, LX(224), 15-44. doi: http://dx.doi.org/10.1016/So1851918(15)30002-7

Svampa, Maristella (2013). Consenso de los commodities y valoración de y lenguajes de valoración en América Latina. Nueva Sociedad, 244, 30-46. Recuperado de: https://nuso.org/articulo/consenso-delos-commodities-y-lenguajes-de-valoracion-en-america-latina/

Welp, Yanina (2016). La participación ciudadana como compromiso democrático. Revista Mexicana de Derecho Electoral, 10, 97-121. doi: https://revistas.juridicas.unam.mx/index.php/derechoelectoral/article/view/11122

Welp, Yanina (2019). El referéndum ha muerto, viva el referéndum. Nueva Sociedad, 282, 98-109. Recuperado de: https://nuso.org/articulo/el-referendum-ha-muerto-viva-elreferendum/

Welp, Yanina y Ordóñez, Vicente (2017). «La democracia directa a debate: procesos y mecanismos de participación ciudadana». Recerca. Revista de Pensament $i$ Análisi, 21, 9-14. doi: https://doi.org/10.6035/Recerca.2017.21.1

Welp, Yanina y Serdült, Uve (coord.) (2014). La dosis hace el veneno. Análisis de la revocatoria de mandato en América Latina, Estados Unidos y Suiza. Quito: Instituto de la Democracia. 